Article

\title{
Numerical Simulation for Void Coalescence (Water Treeing) in XLPE Insulation of Submarine Composite Power Cables
}

\author{
Monssef Drissi-Habti * (D), Das Raj-Jiyoti, Soumianarayanan Vijayaraghavan \\ and Ech-Cheikh Fouad \\ Department COSYS LISIS, Université Gustave Eiffel, F-77447 Marne-la-Valleée, France; \\ raj-jyoti.das@ifsttar.fr (D.R.-J.); V.Soumianarayanan@ifsttar.fr (S.V.); fouad.ech-cheikh@ifsttar.fr (E.-C.F.) \\ * Correspondence: monssef.drissi-habti@ifsttar.fr
}

Received: 23 July 2020; Accepted: 5 October 2020; Published: 19 October 2020

\begin{abstract}
Due to the growing demand for offshore renewable energy, the development of durable submarine power cables is critical. Submarine power cables are expected to have a service life of over 20 years. However, it has been shown that these cables suffer from water-tree flaws that progressively extend to conductors and corrode copper, which may lead to premature failure. Water treeing is caused by the of interconnection of voids (of a few nanometers) that are present in the insulator after manufacturing or formed during operation. The economic consequences of a breakdown can be drastic due to the heavy maintenance required. In the current study, the insulator is modelled as cubic unit cells containing water voids in the form of ellipsoids. The displacement field of ellipsoids is found to be dependent on its distribution in the cubic cell and on the applied electric field. Von Mises stress and effective plastic strain at the tips of the ellipsoid are found to be significant when either the relative distance between the two ellipsoids is short or the applied electric field is high. The proposed model is intended to provide insights into the ageing of cross-linked polyethylene (XPLE), which is extremely difficult to predict experimentally due to the excessive time needed to achieve coalescence of voids.
\end{abstract}

Keywords: offshore wind energy; power cables; water trees; modeling; insulators; composites

\section{Introduction}

Offshore energy is a potentially promising source of renewable energy and extensive work has been devoted to suggest reliable structures that can withstand harsh environments while ensuring reliable delivery of electricity to onshore electric power stations [1-5]. Submarine power cables are deployed to work in extreme environmental conditions for a lifetime of 20 to 25 years [5]. A large number of elements are required to form the complex structure of a submarine power cable (Figure 1, [6]). The investment required for operation and maintenance of submarine power cables is substantial. Therefore, efficient methods are necessary to predict the lifetime of cables [5]. Among the various constituents of a submarine power cable, the insulator surrounding the conductor is an integral component and regular monitoring of the insulator is important to prevent a breakdown. At the advent of submarine power cables, oil-paper insulation was initially used. However, from the early 1960s, cross-linked polyethylene (XLPE) became the most preferred insulator material because of its better electrical and mechanical performance [7-10]. Although the demand of XLPE as an insulator material remains high, the lifetime of cables is significantly reduced by the presence of water trees in the insulator. Water trees are a permanent degradation structure and are composed of very small voids (i.e., of a few nanometers). The amount of water absorbed in field-aged cables has been found to be 
approximately $0.5-2 \%$ of the total insulation volume. The operational and material factors of cables are considered to influence the growth rate of water trees. Operational factors are those factors that are independent of the insulating material and include electrical stress, frequency, temperature, and aging time. Material factors are the internal physical and chemical properties of water trees, and geometrical parameters [11].

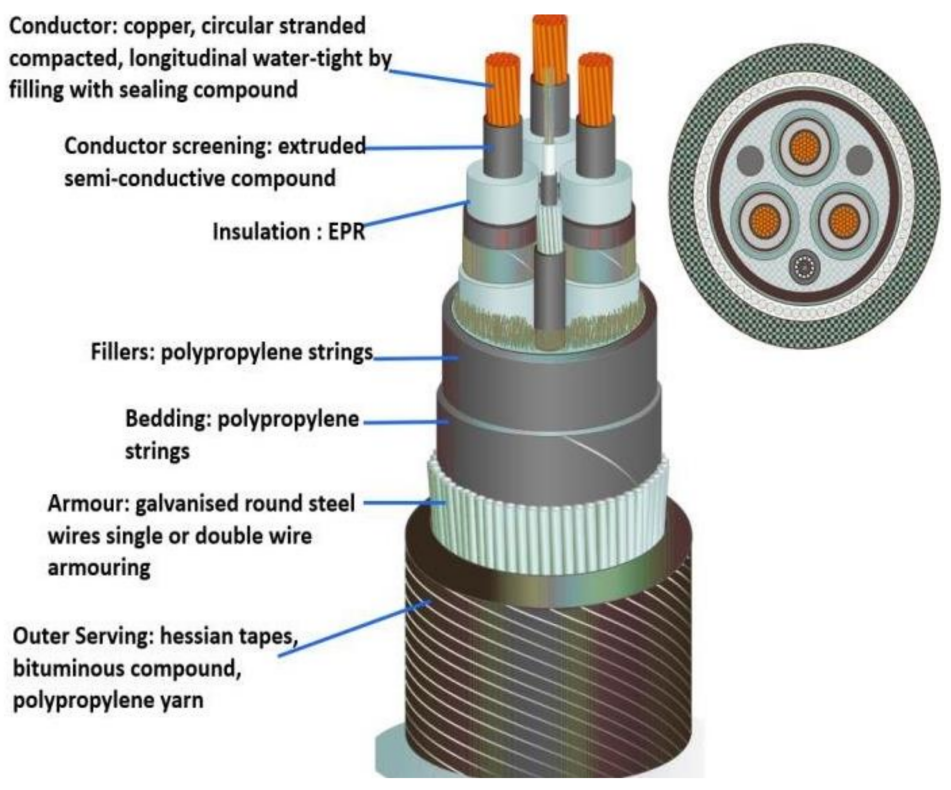

Figure 1. A submarine power cable [6].

The initiation and growth of water trees depends largely on the electric field and water content [12]. A non-uniform electric field and the polarization effect shapes the water voids into ellipsoids [13]. Therefore, water voids are usually modelled as ellipsoids in numerical studies. The application of an electric field induces high Maxwell stress near the tips of ellipsoidal water voids, resulting in their deformation. According to [14], moderate electric fields of $10-50 \mathrm{KV} / \mathrm{mm}$ do not cause permanent deformation of water voids, whereas [15] proved that electric fields above $100 \mathrm{KV} / \mathrm{mm}$ cause plastic deformation. Therefore, in our study an electric field of 50-200 KV/mm was applied to evaluate the effective plastic strain generated at the tips of water voids. In relation to a numerical study of water treeing in power cable insulation from a mechanical point of view, $[16,17]$ reported that fatigue of the insulation caused by dielectrophoretic stresses around the voids might lead to the growth of water trees. According to [18] the growth of water trees proceeds by the interconnection of ellipsoidal-shaped voids. Degradation has been modeled as a cubic cell with cylindrical channels and ellipsoidal inclusions filled with water, and dielectric properties have been studied under the effect of Maxwell stress [19].

The major steps involved in the growth of water trees are represented in Figures 2 and 3. Voids are the inception points for water trees. Some voids are present in the cable at the end of the extrusion process. When submarine cables are in operation, water molecules enter these voids because of excess humidity. Based on numerous studies of the possible mechanisms involved in the growth of water trees, electric fields have been found to be the most significant influence on the growth of water trees in insulators. The forces resulting from the high electric field at the tips of the voids cause plastic deformation and subsequently lead to the formation of interconnecting channels between the voids. After initiation, water trees begin to propagate towards the conductor, leading to its corrosion and ultimately damaging the cable. 

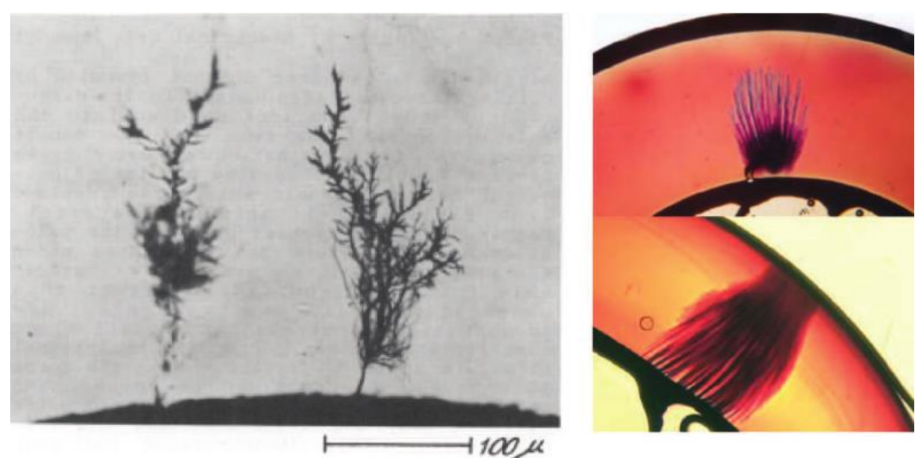

Figure 2. Magnified image of a water tree in cross-linked polyethylene (XLPE) with voids and channels connecting the voids.

STEP 1:

- Water molecules enter into voids because of humidity

- Electric field influences voids present inside the insulator.

STEP 2:

- Electric field causes plastic deformation of voids

- Relative distance between voids influences Plastic deformation

STEP 3:

- Formation of channel between voids

- Voids merge with each other forming a Water tree

STEP 4 :

- Propagation of water tree towards the conductor

- Corrosion of conductor

- Degradation of cable

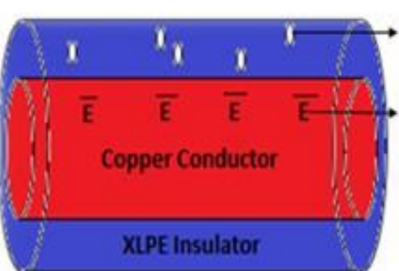

Voids in the insulator

Electric field

passing inside conductor

\section{Submarine XLPE power cable}

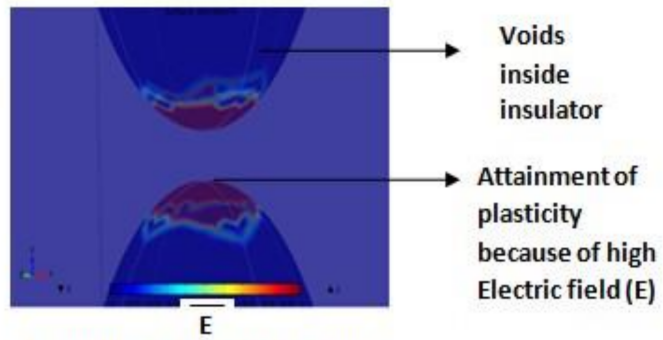

Magnified image of voids
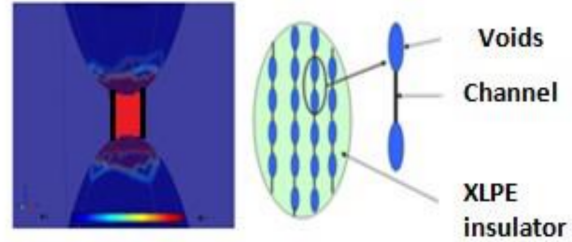

\section{Channels interconnecting Voids}

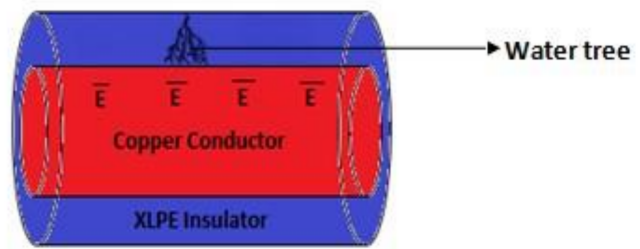

\section{Water tree growing towards conductor}

Figure 3. Schematic representation of steps involved in the growth of water trees and used to model water voids in an insulator. Information about geometrical, material, and modelling parameters is detailed in the next section. This work also aims at studying the minimum distance between voids that results in the void's coalescence. 
In this article, a 3D finite element model of a water void in an insulator is developed using COMSOL Multiphysics software. Although it would be of significant interest, experimental study of the ageing of insulators due to water tree propagation is impractical due to the extremely long ageing experiment time that would be required. Thus, the current study instead aims to widen the comprehension of this kind of ageing using numerical modeling. In this study, the water void was modelled as an ellipsoid in a cubic cell in reference to the model of [19]. The main objectives of this study are to: (1) calculate the displacement of a single water void in a cubic cell with respect to applied voltage; (2) determine the influence of relative distance between two water voids and applied voltage on the void's displacement; and (3) to study the plastic deformation of water voids in accordance to the von Mises yielding criterion. The first section of this article describes the electromechanics module of COMSOL Multiphysics, which was the main computer tool used in this study. It should be noted that few previous studies have been conducted pertaining to the current topic, thus the presented simulation results cannot be compared to the literature. Therefore, we would like to emphasize that the current results should be viewed as introductory and an inspiration for future research.

\section{Numerical Modeling}

\subsection{FE Software}

COMSOL Multiphysics is a platform offering a simulation tool for electrical, mechanical, fluid flow, and chemical applications. A coupled Multiphysics electrical and mechanical phenomenon was considered for modelling water voids using COMSOL. A 3D model was created to study the deformation of water voids present in cable insulation. COMSOL provides a number of options relating to the type of solver configurations required to obtain the best numerical results. Problems are solved based on advanced numerical methods.

\subsection{Electromechanics Theory}

The electromechanics module can be found under the structural mechanics physics tree. This module is used to study deformation of objects under the effect of an applied electric field. A model was created using COMSOL Multiphysics to study the influence of an electric field on water voids present in an insulator. Before discussing the mathematical formulations, we describe the coordinate system that was used. Continuum mechanics uses two coordinate systems, a material coordinate system and a spatial coordinate system. A material coordinate system was used to describe all material particles. The particles were identified by their position in the reference configuration. In the presence of external forces, the material coordinates are held constant and the spatial coordinates change with respect to time and applied force. The current position of the material depends on the displacement vector, which is the difference between the reference and current coordinate system. In the structural mechanics interface of COMSOL, the primary dependent variables are these displacement vectors $(\mathrm{u}, \mathrm{v}, \mathrm{w})$. An electric potential is applied at the boundary of the conductor and, because it is a varying electric field inside the insulator, it has a coordinate dependence in physical space. Therefore, a spatial coordinate system was used for further description of the loads and constraints. The material properties of the conductors and insulators are given for material particles described using the material coordinate system.

\subsection{Geometrical Parameters}

The density of voids in the insulators has been reported to be approximately $106 \mathrm{~mm}^{-3}$ [10], with void radii ranging from 0.1 to $5 \mu \mathrm{m}$ [13]. Water content has been observed to be around $0.5-2 \%$ of the total insulation volume [20]. Establishing a 3D model with a large number of voids is difficult because of the enormous simulation time and disk space required. Thus, to avoid such a situation and allow study of each water void in detail, we confined our simulation to a maximum of two voids. 
The insulation can be represented as a combination of a number of cubic unit cells containing water voids (Figures 4 and 5). In this study, cubic unit cells of $10 \times 10 \times 10 \mu \mathrm{m}$ and $20 \times 20 \times 20 \mu \mathrm{m}$ containing one ellipsoid and two ellipsoids, respectively, were modelled. The dimensions of the ellipsoids were varied in such a way that they each comprised $1 \%$ of the total volume of the cubic cell, i.e., $1 \%$ of the cubic cell is always filled with water, which is in accordance with the reported data on the percentage of water content in the insulation volume. Representations of water voids are provided in Figures 4 and 5.
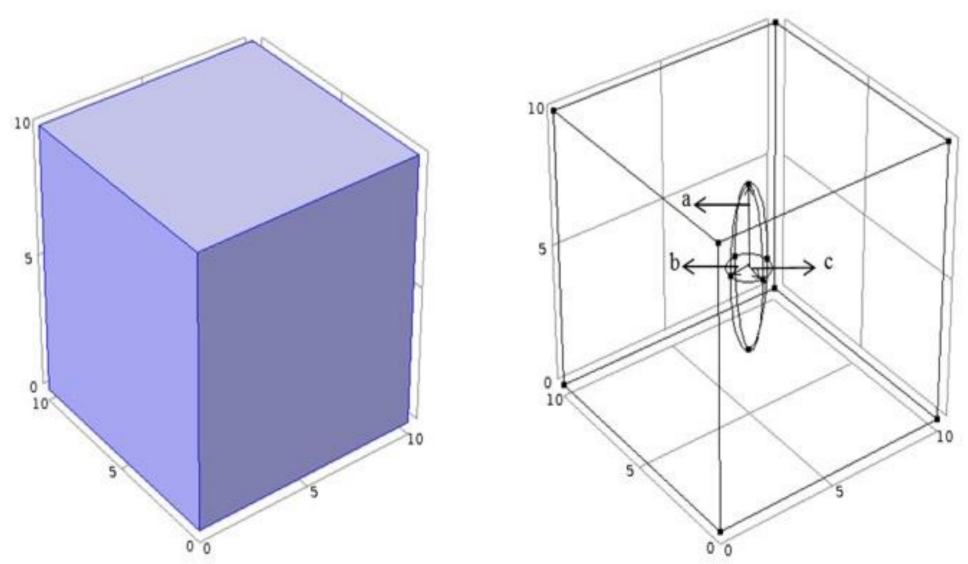

Figure 4. A cubic cell of $10 \times 10 \times 10 \mu \mathrm{m}$ with one water void.
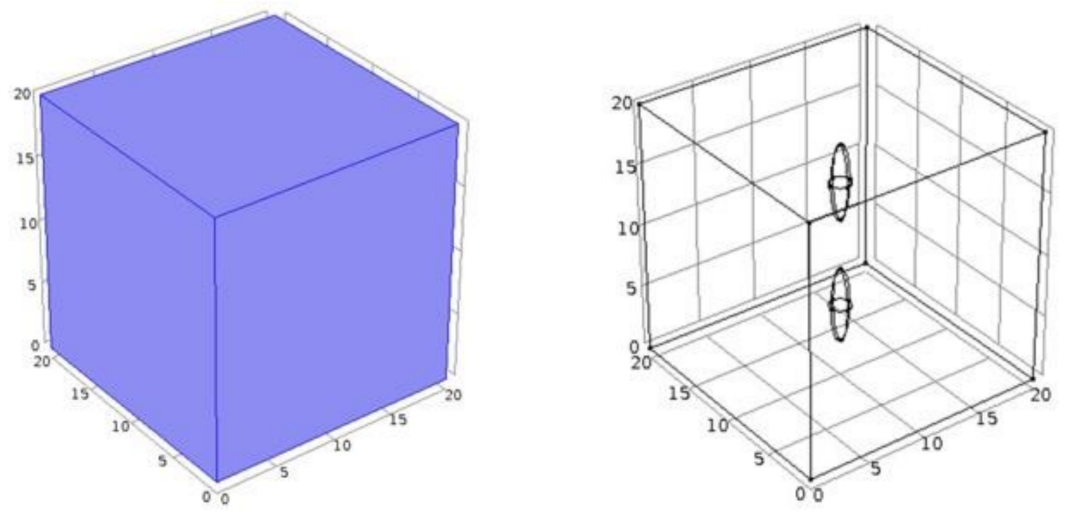

Figure 5. A cubic cell of $20 \times 20 \times 20 \mu \mathrm{m}$ with two water voids.

\subsection{Material Parameters}

All of the material parameters were held constant in this study. The values of different parameters used in the study are stated in Tables 1 and 2 (https://www.nexans.fr/eservice/France-fr_FR/navigate_ 325956/Submarine_High_Voltage_Cables.html).

Table 1. Material parameters for XLPE [6].

\begin{tabular}{ccc}
\hline Name & Value & Unit \\
\hline Young's Modulus & 3.5 & $\mathrm{GPa}$ \\
\hline Relative permittivity & 2.3 & 1 \\
\hline Poisson's ratio & 0.3 & 1 \\
\hline Density & 930 & $\mathrm{~kg} / \mathrm{m}^{3}$ \\
\hline Electrical conductivity & $1 \times 10^{-15}$ & $\mathrm{~S} / \mathrm{m}$ \\
\hline Initial yield stress & 18 & $\mathrm{MPa}$ \\
\hline
\end{tabular}


Table 2. Material parameters for water void [6].

\begin{tabular}{ccc}
\hline Name & Value & Unit \\
\hline Electrical conductivity & - & - \\
\hline Relative permittivity & 80 & 1 \\
\hline
\end{tabular}

\subsection{Electromechanics Model}

The deformation of water voids in cubic cells is described by a 3D electromechanics model. Initially, a single water void in a cubic cell was modelled and its deformation studied with varying voltage across the cell. Water trees are formed as a result of the combination of water voids present in the insulator which leads to its degradation. Therefore, it is important to study the merging of water voids under the effect of an electric field. Thus, a cubic cell with two water voids was modelled to determine the critical distance that leads to formation of a single geometry. The governing equations of the electromechanics module in COMSOL Multiphysics are the equilibrium equation of continuum mechanics Equation (1) and Gauss law of electricity Equation (2):

$$
\begin{gathered}
-\nabla \cdot \sigma=F \\
\nabla \cdot D=\rho
\end{gathered}
$$

where $\sigma$ is the Cauchy stress tensor, F is body force, D is electric displacement, and $\rho$ is free charge density. A voltage terminal is assigned to a face of the cubic cell and its opposite face is grounded. The electric field was fixed at $50 \mathrm{kV} / \mathrm{mm}$ for most of the simulations. In some cases, it was varied from 50 to $250 \mathrm{kV} / \mathrm{mm}$ to study its effect on the resultant deformation of voids, combined with the plastic strain at the interface of the voids and the insulator (Figures 6-8).

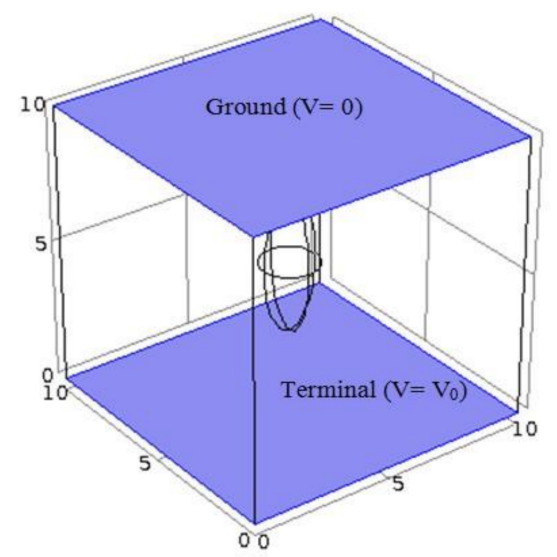

Figure 6. Terminal and ground boundary conditions.

The electric field intensity and potential is related by the following equation:

$$
E=-\nabla V
$$

where $\mathrm{E}$ is the electric field and $\mathrm{V}$ is applied voltage. The constitutive equation relating electric displacement (D) in water voids and the electric field (E) in an insulator is:

$$
\mathrm{D}=\varepsilon_{0} \varepsilon_{\mathrm{r}} \mathrm{E}
$$

where $\varepsilon_{0}$ is the permittivity of free space and $\varepsilon_{\mathrm{r}}$ is the relative permittivity of the insulation material (XLPE). After assigning terminal and ground boundary conditions, the remainder of the cubic cell is automatically assigned a zero charge boundary condition. This implies zero penetration of the 
displacement field and discontinuity of electric potential across the boundary. The blue shaded faces in Figure 7 are assigned to zero charge boundary conditions. The insulator excluding a water void is defined as a linear elastic dielectric material (Figure 8a). This definition combines structural mechanics and electrostatics physics including additional forces originating from electromechanical (or Maxwell) stresses. The forces resulting from electromechanical stresses are considered to be surface forces and acts at the external interface of the linear elastic dielectric domain (Figure $8 b$ ). These forces are added through the electromechanical interface boundary condition and thus act only on the water void domain. As a result, a combined force of both surface and electromechanical forces is applied to both the linear elastic dielectric solid and its interface.

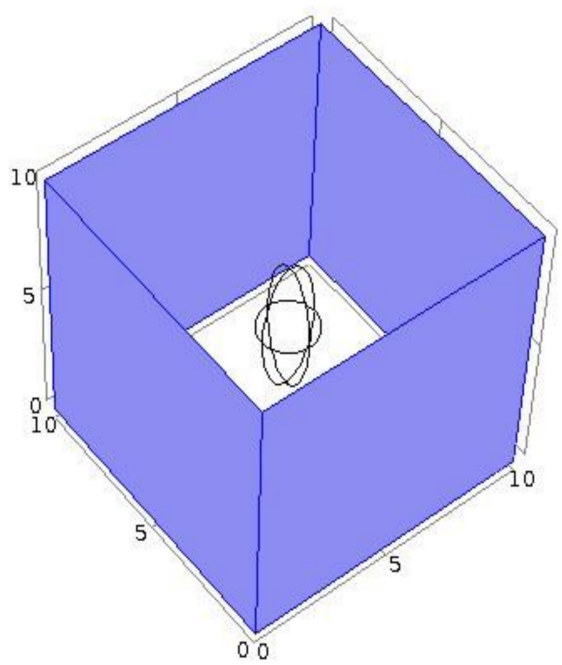

Figure 7. Zero charge boundary condition.

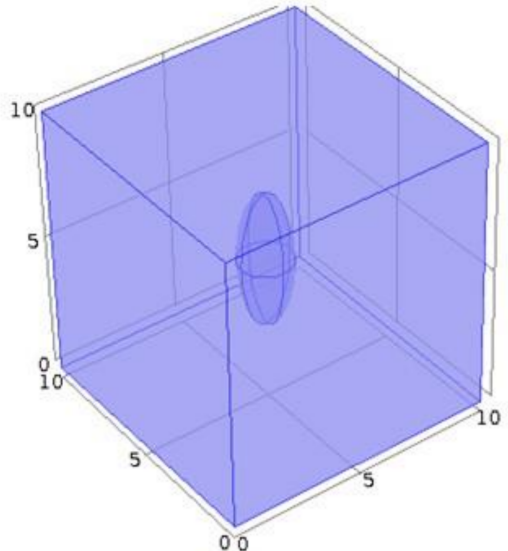

(a)

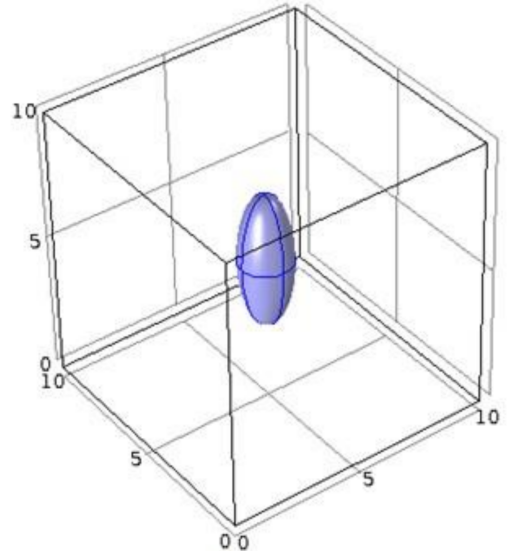

(b)

Figure 8. (a) Linear elastic dielectric solid, (b) electromechanical interface.

In this model, the water void is considered to be an electromechanical interface. Thus, the electromechanical force of Equation (5), which is dependent on the electric field, acts on the void resulting in its deformation. These forces originate from the discontinuity in the Maxwell stress across the interface of the dielectric solid and act at the boundary of the water void.

$$
\mathrm{FA}=1 / 2 \varepsilon_{0}(\mathrm{E} \cdot \mathrm{E}) \mathrm{n}+\varepsilon_{0}(\mathrm{n} \cdot \mathrm{E}) \mathrm{E}
$$

The model was meshed using tetrahedral, triangular, edge, and point elements. A finer mesh was used for the ellipsoid and a coarser mesh for the remaining model to allow the deformation of the ellipsoid to be studied with more precision. It should be noted that all of the conditions used to 
establish the single water void model were also utilized for the multiple water void models. To simulate the exact conditions experienced by the voids, voids were assumed to be aligned in the direction of the applied electric field. The electric field value is highly dependent on the position at which the analysis is conducted. As shown in Figures 9 and 10, if the problem is positioned at, for example, a location at which the issue is maximized, according to this introductory simulation the amplification of the electric field at the tips of the ellipsoid can be increased by a factor of 8 at an electric field of $50 \mathrm{kV} / \mathrm{mm}$. If the amplification factor is considered to be constant at any applied electric field, the electric stress at an electric field of $250 \mathrm{kV} / \mathrm{mm}$ can cause significant damage at the tips of the ellipsoid and hasten the merging of voids, thus increasing the rate of propagation of water treeing.

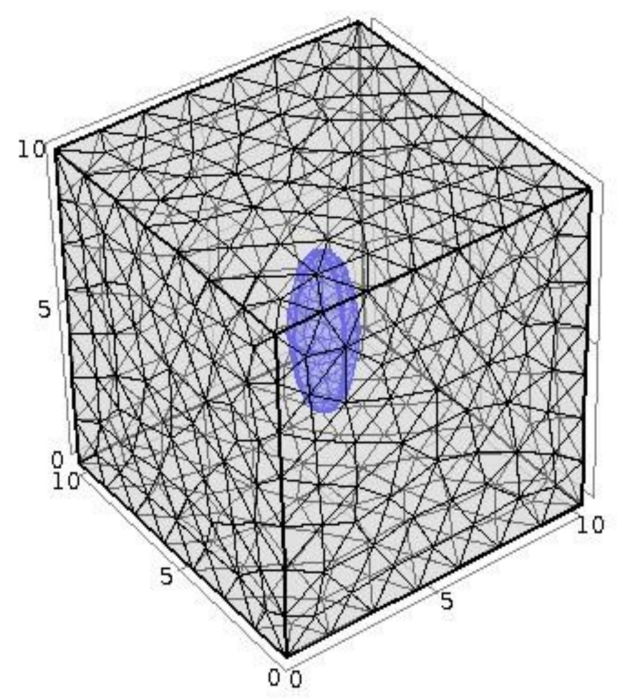

Figure 9. Mesh form of the model.

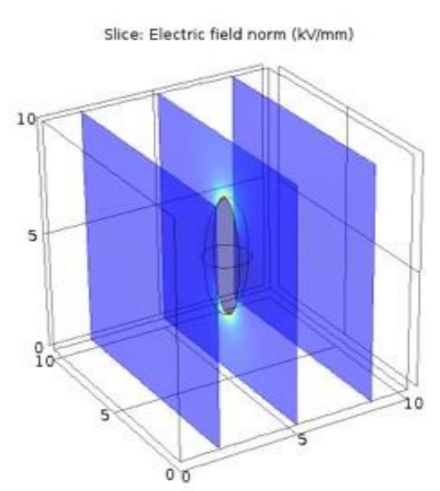

(a)
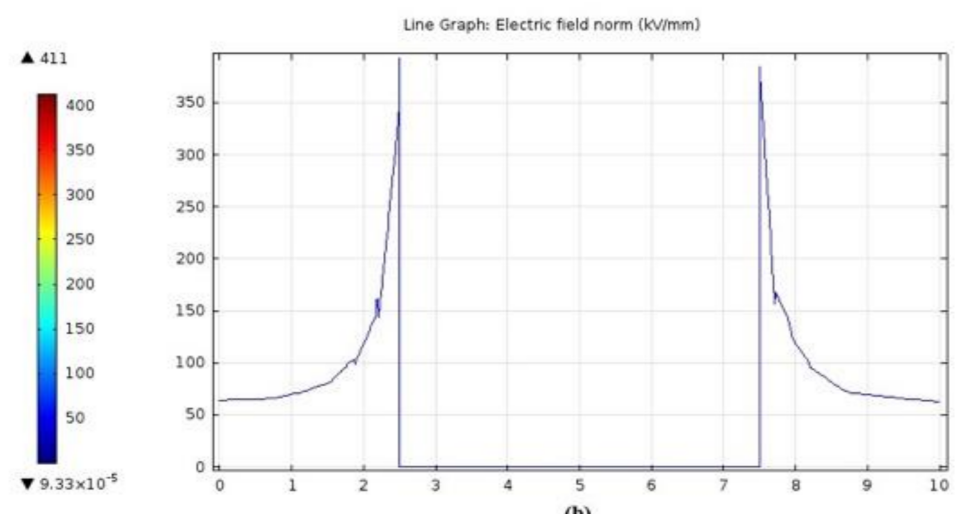

(b)

Figure 10. Electric field norm: (a) slice view of electric field norm distribution; (b) electric field norm enhanced at the tips of an ellipsoid in the middle of the insulator.

\section{Results and Discussion}

A number of simulations were carried out to study the deformation of water voids under the effect of an applied electric field. Electric field enhancement at the tips of ellipsoids has been reported in previous studies [16,17]. The growth of these ellipsoids and the merging of neighboring ellipsoids is the cause of degradation of the insulator material in the form of water treeing, and ultimately the material's breakdown. These interconnections of ellipsoids (i.e., water voids) to form a water tree is a complex phenomenon that involves several factors, the most significant of which is the electric field [18]. In addition to the electric field, the distance between the tips of ellipsoids has also been found to be an important factor in the degradation of the insulator material. 
As stated previously, the applied electric field was varied between 50 and $250 \mathrm{kV} / \mathrm{mm}$. Voids in an insulator can be of different shape and size. Furthermore, corresponding to the void's aspect ratio, the electric field is amplified at the void's tip. The voids suffer maximum deformation when they are aligned in the direction of the electric field. In order to review the maximum deformation an applied electric field causes instability of the water molecules present inside the ellipsoids, causing them to deform in areas in which the geometry of the ellipsoids is most favorable. The deformation is expressed in the form of displacement encountered at the tips of the ellipsoids. Figure 11 is a graphical representation of the deformation suffered at the tips. It is clear from this figure that the ellipsoid experiences maximum displacement (i.e., deformation). The rate of deformation of ellipsoids is not constant because ellipsoids with varying aspect ratios deform differently. In an increasing electric field Figure 12, the instability of water molecules increases resulting in greater displacement of the tips of the ellipsoid.

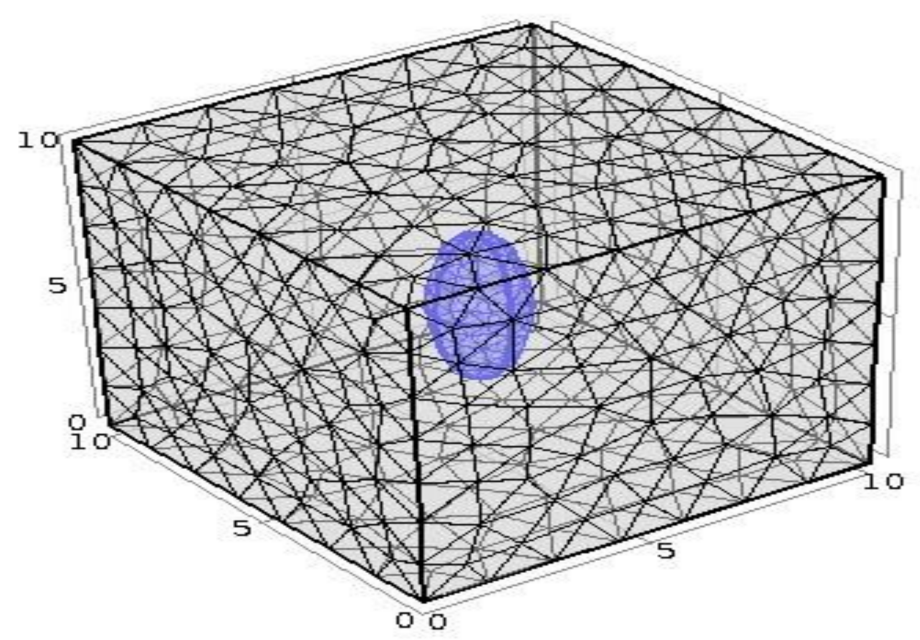

Figure 11. Displacement of the tips of an ellipsoid at $50 \mathrm{kV} / \mathrm{mm}$.

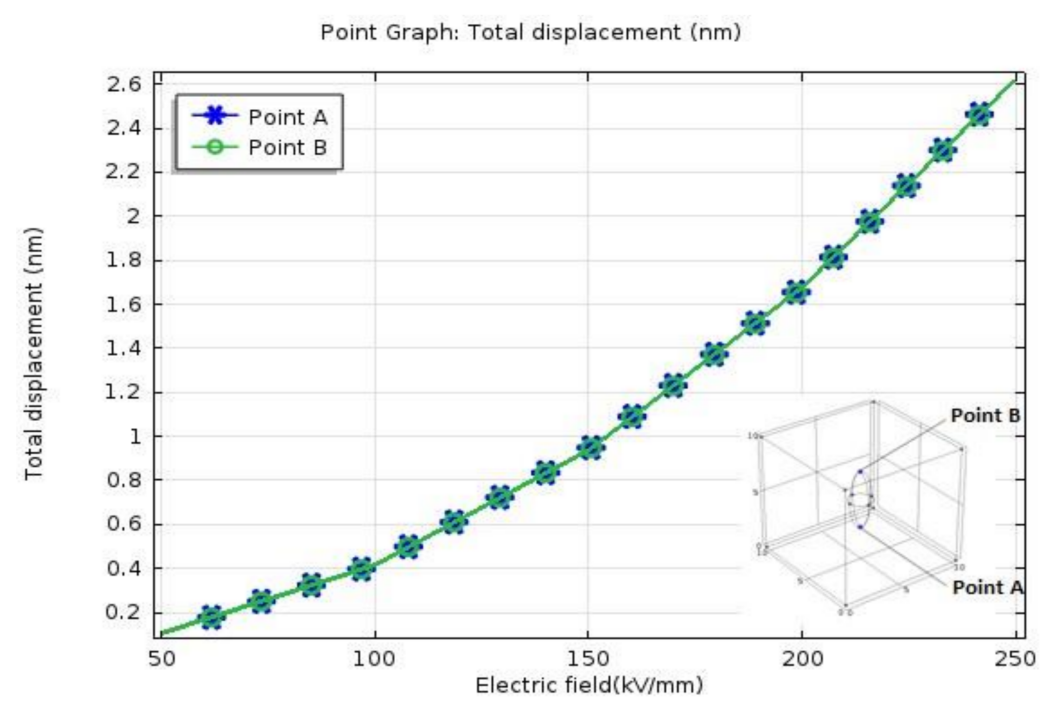

Figure 12. Total displacement with increasing electric field.

The merging of voids involves permanent deformation of localized zones present between voids. A material suffers permanent deformation when it attains or crosses yield stress due to an external load. Although several yielding criteria describing the failure of materials exist, von Mises stress or von Mises yield criterion was used in this study because it simplifies the understanding of the physics behind the interconnection of voids that leads to the propagation of water trees. The applied electric 
field is the only loading condition that causes Maxwell stress along the surface of voids. Von Mises stress is calculated using the Maxwell stress tensor.

Increasing the applied electric field increases von Mises stress, particularly at ellipsoid tips as shown in Figures 13 and 14. This increment of von Mises stress is due to an increase in the induced Maxwell stress. Of note, this plot shows that the von Mises stress surpasses the yield strength of XLPE at an approximate electric field of $200 \mathrm{kV} / \mathrm{mm}$.

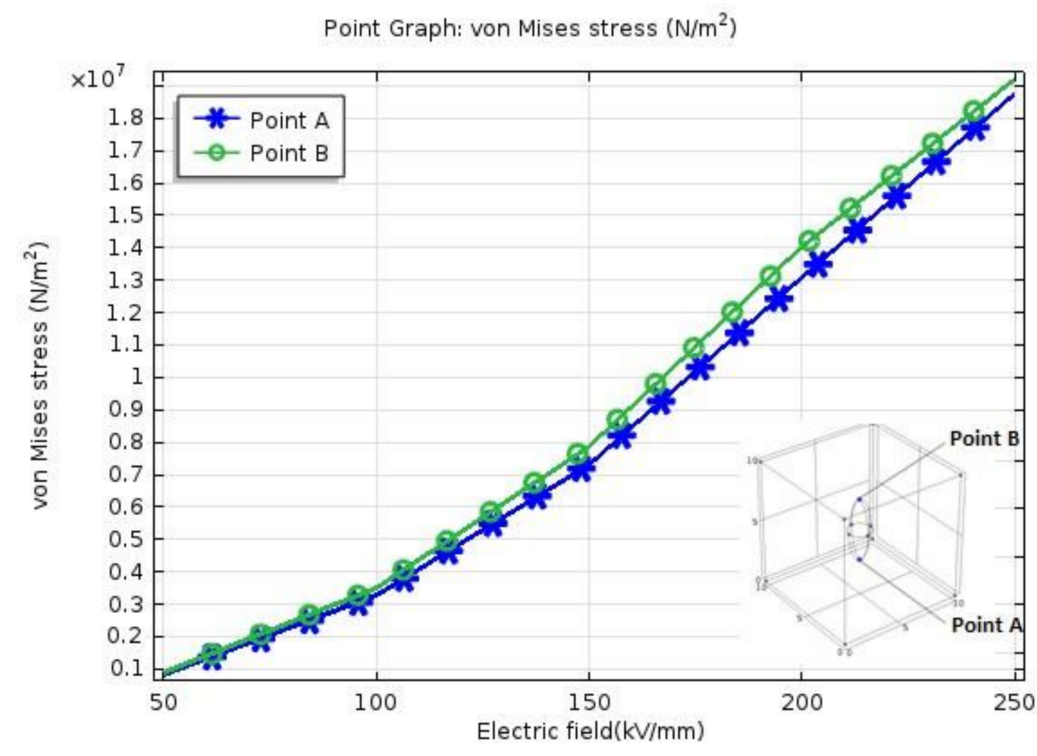

Figure 13. Von Mises stress with increasing electric field.

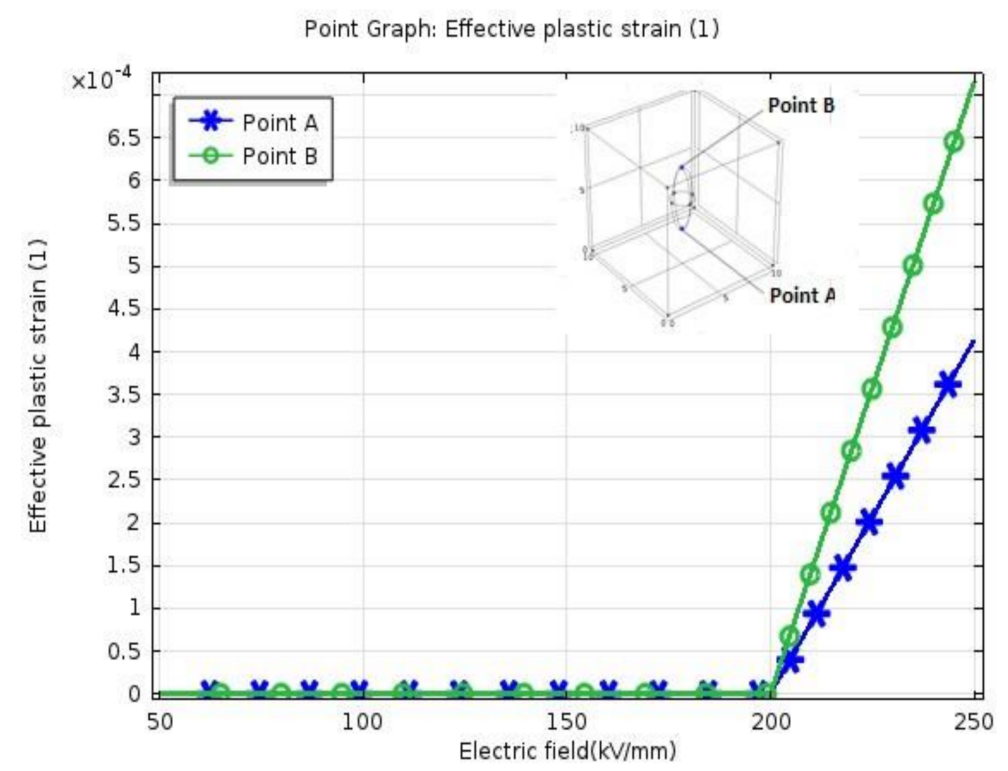

Figure 14. Effective plastic strain with increasing electric field.

Voids experience permanent deformation when Von Mises stress reaches a critical value of $18 \mathrm{MPa}$ at an electric field of $200 \mathrm{kV} / \mathrm{mm}$ (Figure 14). Plastic deformation is initiated at $200 \mathrm{kV} / \mathrm{mm}$ and increases at a constant rate with an increase in the applied electric field. At this stage, formation of channels between voids is initiated. These channels bridge the voids, thus forming a bigger water tree structure inside the insulator.

Modeling of one water void in a cubic cell of $10 \times 10 \times 10 \mu \mathrm{m}$ was followed by a model of two water voids in a cubic cell of $20 \times 20 \times 20 \mu \mathrm{m}$ (Figure 15). Both the geometrical and material 
parameters of the water voids are identical. The water voids can be present randomly inside the cubic cell; however, in this study the water voids were aligned in the direction of the electric field and placed adjacent to each other. The water voids suffer maximum deformation when they are in the direction of electric field.

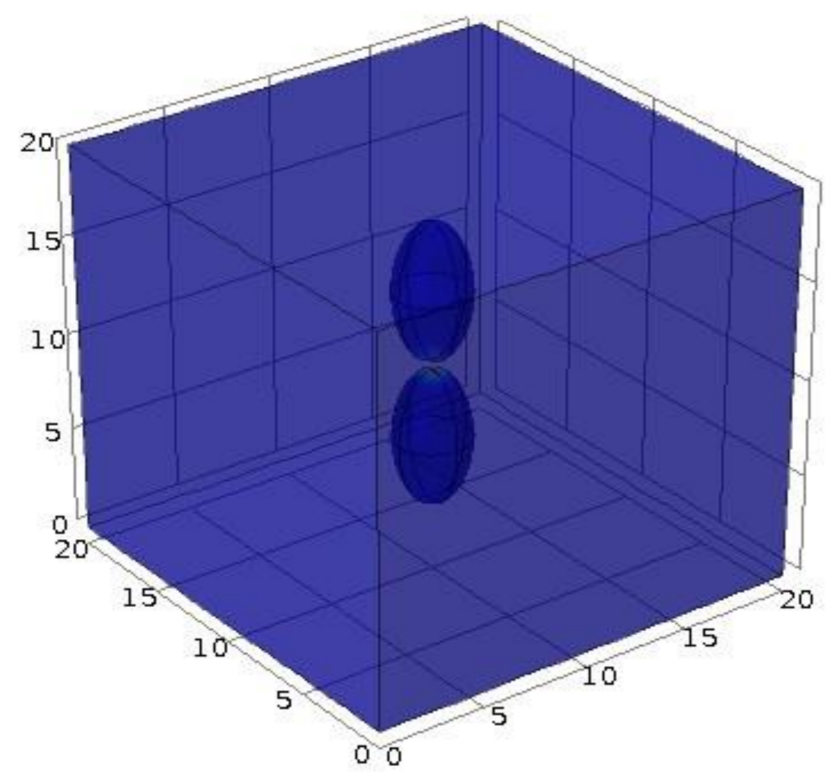

Figure 15. A cubic cell of $20 \times 20 \times 20 \mu \mathrm{m}$ with two water voids.

Figure 16 shows that the displacement of the tips of two neighboring ellipsoids depends on the relative distance between the two and on the electric field. As observed in the model of one water void in Figure 12, displacement increases with an increase in the applied electric field in the two water void model, as shown in Figure 16a-c.

It can be noted from these figures that displacement increases with decreasing relative distance between voids (Figure 16b,c), whereas Figure 16a shows there is some dissimilarity in displacement of the points A, B, C, and D. The reason for this dissimilarity might be that a relative distance of $0.5 \mu \mathrm{m}$ between voids at an applied electric field of around $200 \mathrm{kV} / \mathrm{mm}$ is sufficient to cause immediate coalescence of voids. Electric field enhancement is greater at points B and C of the two ellipsoids compared to points $A$ and $C$; therefore, points $B$ and $C$ experience higher deformation compared to the points that are further apart from each other.

As mentioned, the von Mises yielding criterion was used to study material failure under external load of an applied electric field. Similar to the case of the single water void model, an increase in the applied electric field increases von Mises stress. The important difference between the two models is the influence of relative distance between the two voids on von Mises stress. It can be inferred from Figure 17 that Von Mises stress acts predominantly at the two adjacent tips (points B and C), rather than at point $A$ and point D. It can also be comprehended from Figure 17 that decreasing the relative distance between voids increases the Maxwell surface stress and also enhances the influence of electric fields between two adjacent tips. These circumstances lead to quick failure of the zones between voids and the creation of channels. A decrease in the relative distance from 2 to $0.5 \mu \mathrm{m}$ intensifies von Mises stress by approximately 3 times at the same voltage. It should be noted that increasing the aspect ratio of ellipsoids will significantly amplify the stresses at their tip. 


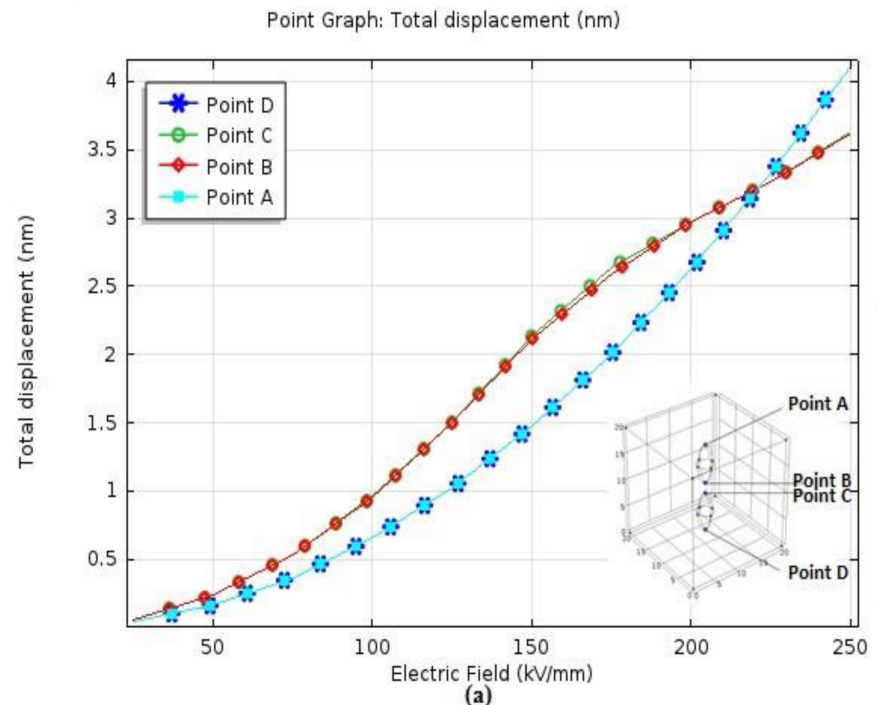

Point Graph: Total displacement (nm)

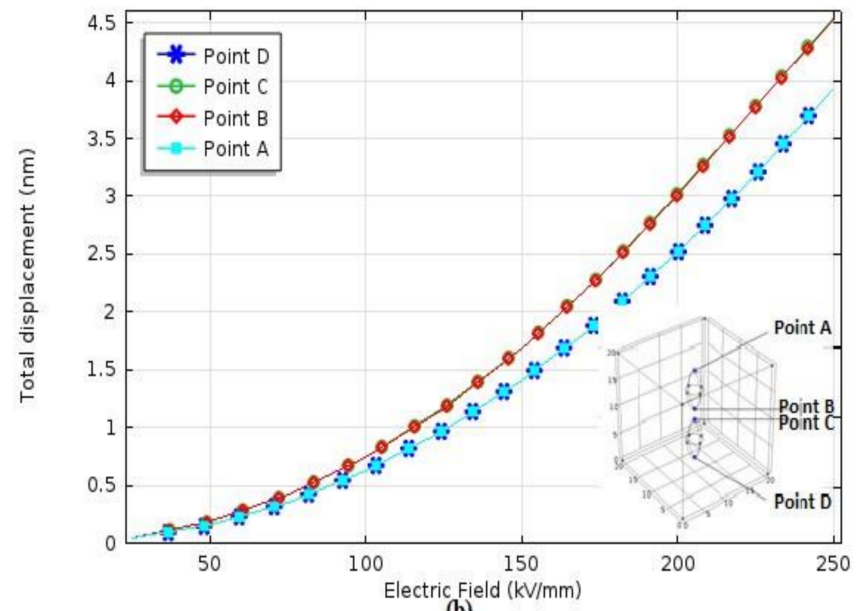

(b)

Point Graph: Total displacement (nm)

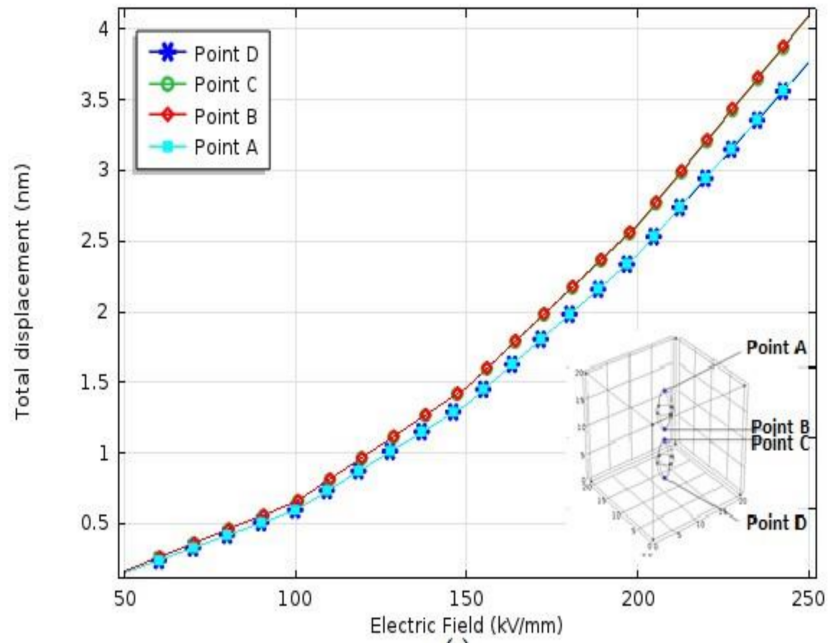

(c)

Figure 16. Total displacement of the tips of ellipsoids with increasing electric field (50-250 kV/mm) and decreasing distance between points B and C: (a) distance: $0.5 \mu \mathrm{m}$; (b) distance: $1 \mu \mathrm{m}$; (c) distance: $2 \mu \mathrm{m}$. 


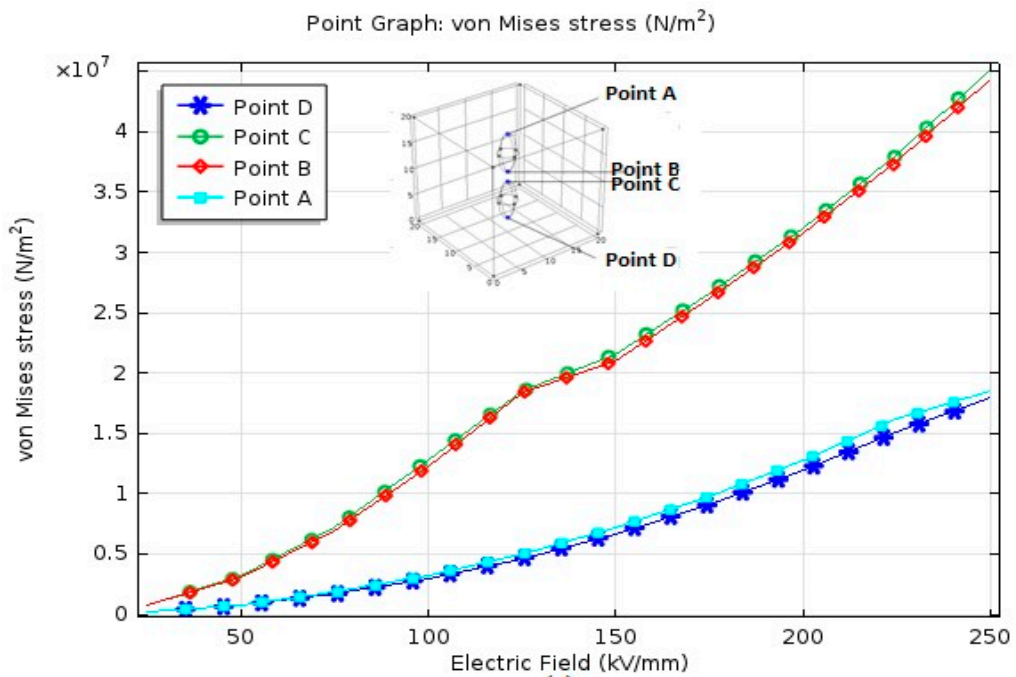

(a)

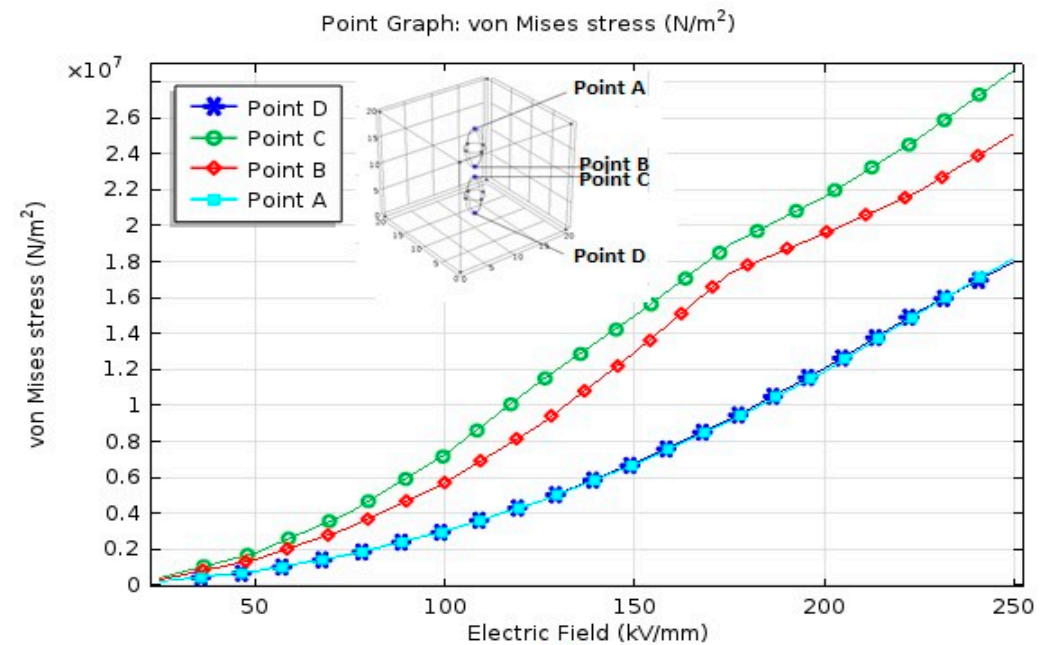

(b)

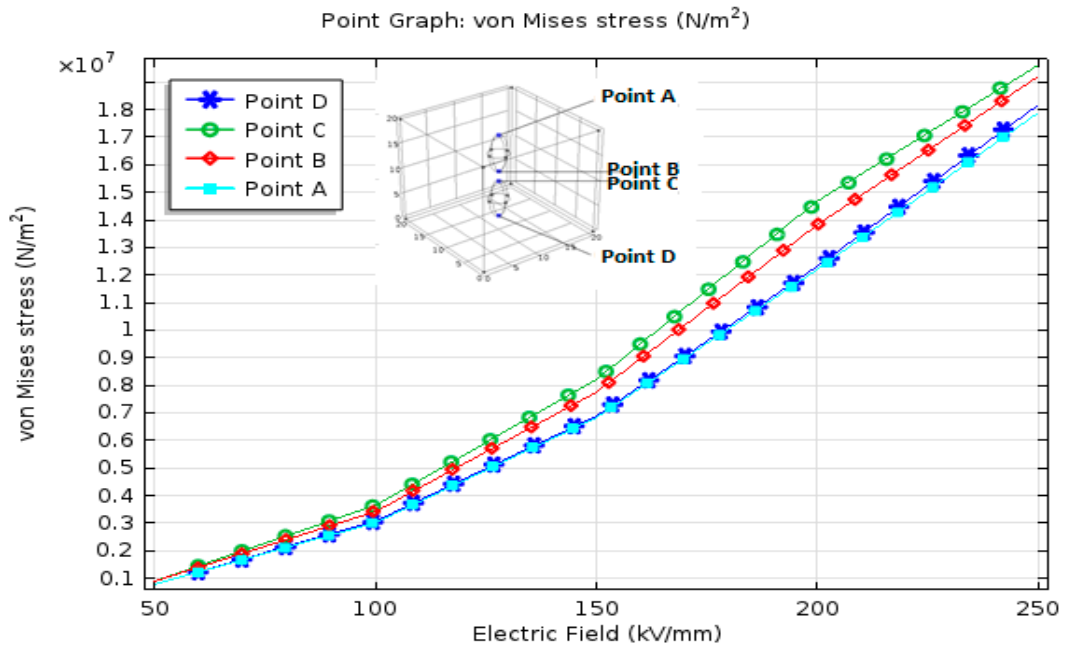

(c)

Figure 17. Von Mises stress at the tips of ellipsoids with an increase in the electric field (50-250 kV/mm) and decreasing distance between points B and C: (a) distance: $0.5 \mu \mathrm{m}$; (b) distance: $1 \mu \mathrm{m}$; (c) distance: $2 \mu \mathrm{m}$. 
The consequence of increasing Von Mises stress with increasing applied electric field is attainment of plastic deformation when the yielding stress of material is reached. Figure 18 demonstrates the important relationship between the relative distance of voids and electric field at which the tips of voids suffer from plastic deformation. At a relative distance of $0.5 \mu \mathrm{m}$, plastic deformation initiates in the zone close to void tips at an approximate electric field of $100 \mathrm{kV} / \mathrm{mm}$; however, at a relative distance of $2 \mu \mathrm{m}$, initiation of plastic deformation is delayed until the applied electric field is around $200 \mathrm{kV} / \mathrm{mm}$.

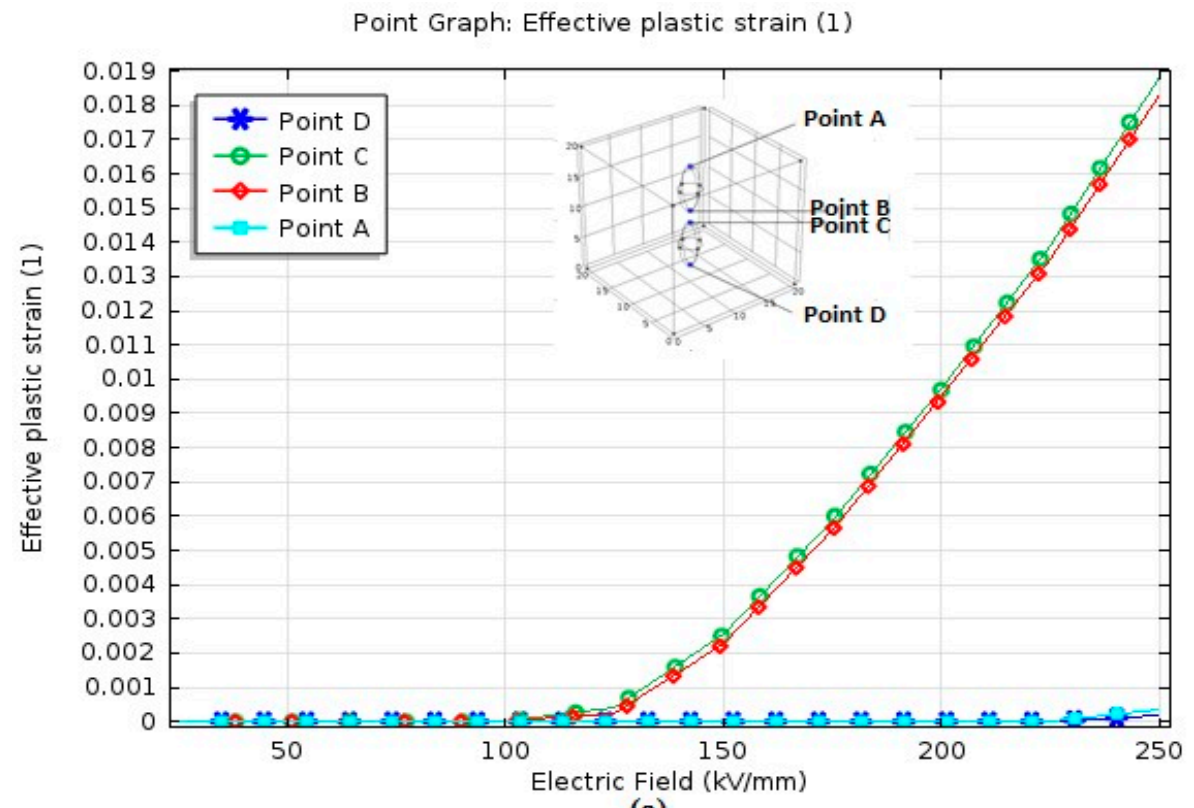

(a)

Point Graph: Effective plastic strain (1)

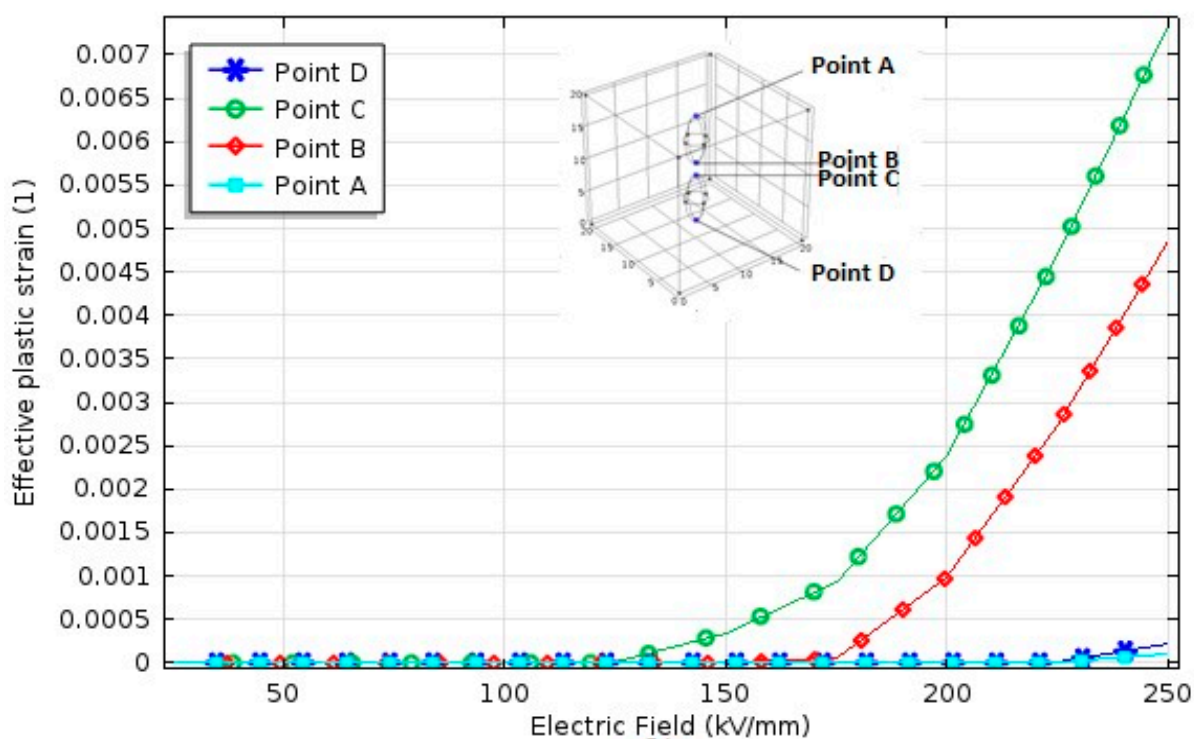

(b)

Figure 18. Cont. 
Point Graph: Effective plastic strain (1)

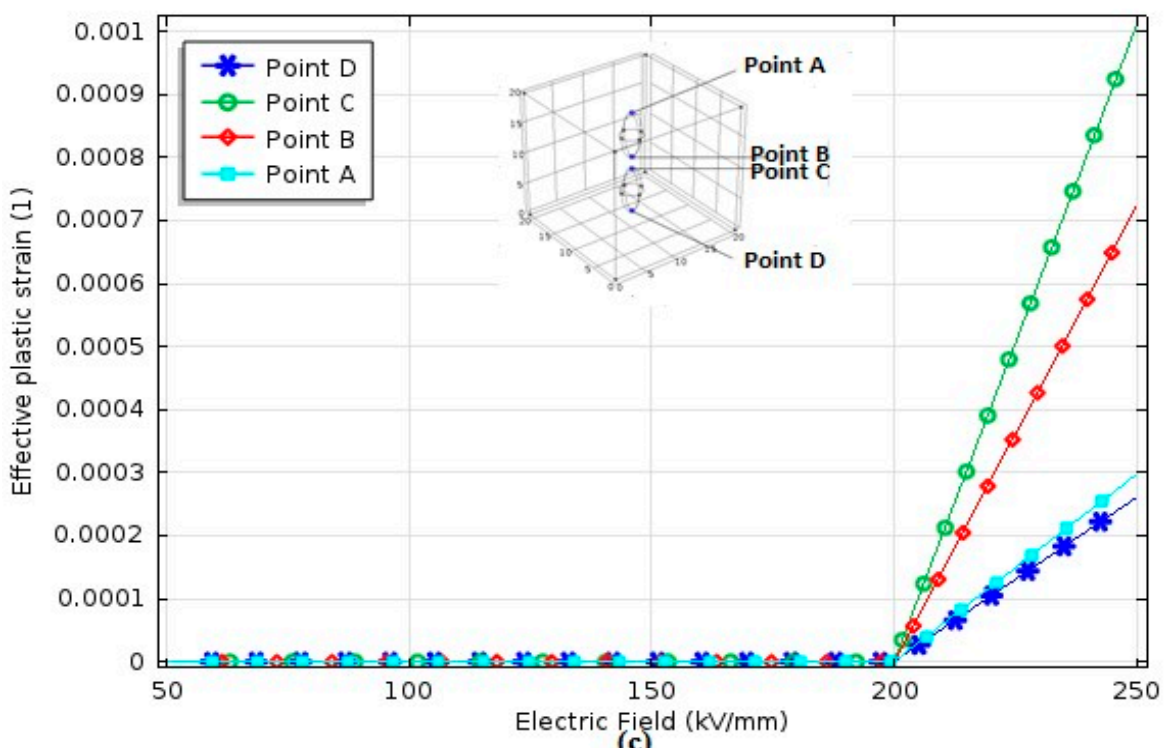

(c)

Figure 18. Effective plastic strain at the tips of ellipsoids with increasing electric field $(50-250 \mathrm{kV} / \mathrm{mm})$ and decrease in distance between points B and C: (a) distance: $0.5 \mu \mathrm{m}$; (b) distance: $1 \mu \mathrm{m}$; (c) distance: $2 \mu \mathrm{m}$.

One of the main objectives in this study is to observe plastic deformation initiating at the tips of voids due to an electric field. Figure 19 depicts the plastic deformation caused by high von Mises stress obtained from the influence of an amplified electric field at the tips of voids. To provide a clear visualization of the mechanisms involved in the plastic deformation of voids, the figure is scaled and is thus not an absolute representation of the effective plastic strain. Figure 19 shows how the tips of water voids attain plasticity with increasing electric field, ultimately leading to coalescence of the two voids by the creation of a channel between them. When the tips of the void attain plasticity, the neighboring zone is affected, thus causing localized damage.

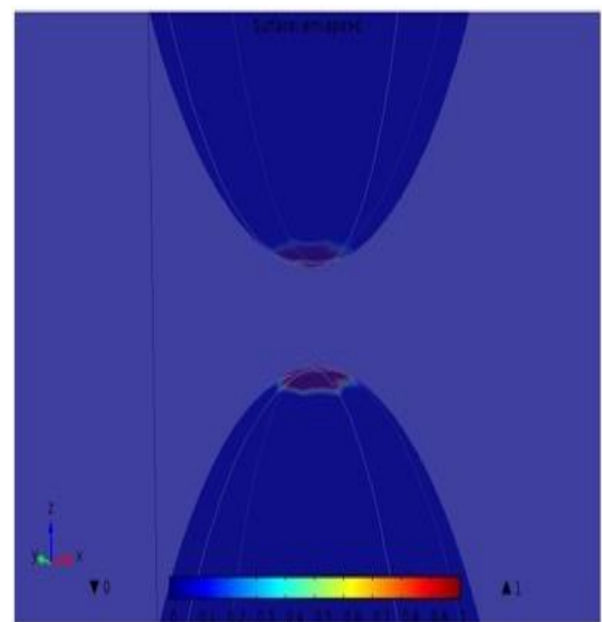

(a)

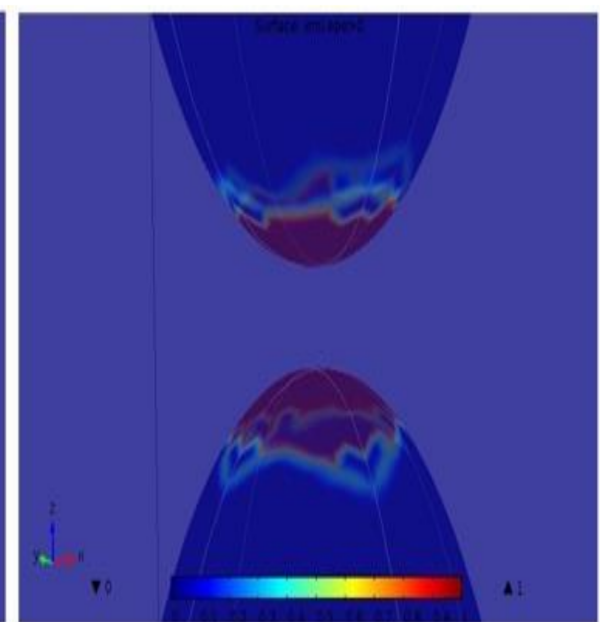

(b)

Figure 19. Increase in the plasticized region with electric field: (a) $150 \mathrm{kV} / \mathrm{mm}$; (b) $250 \mathrm{kV} / \mathrm{mm}$. (Note: distance between points $B$ and $C$ is held fixed at $1000 \mathrm{~nm}$ ).

With the increase in the electric field the localized damage zone expands, thus accelerating the merging of the voids. This preliminary model is promising because it provides clear insights into XPLE ageing, which is extremely difficult to model experimentally due to the ageing time needed. 


\section{Conclusions}

The initiation and propagation of water trees in insulators of submarine power cables poses a serious threat to the lifetime of the cables. This also incurs substantial economic losses as a result of electrical breakdown. Therefore, it is important to have a clear understanding of the parameters involved in the initiation and propagation of water trees. The results obtained in this study shed some light on this issue, although significant research remains to be done. The electromechanical stresses caused by an applied electric field affect the deformation of water voids in insulation. An increase in the applied electric field from 50 to $250 \mathrm{kV} / \mathrm{mm}$ across the insulation results in higher stresses at the tips of ellipsoids. Modeling of a single water void helped to analyze how the water voids undergo deformation under the effect of an applied electric field. By comparison, the model with two adjacent water voids assisted in understanding the significance of the relative distance between two water voids in the merging of the voids. Although an applied electric field significantly affects the deformation of water voids, the results of numerical simulations in this study show that the relative distance between adjacent water voids also plays a vital role in their coalescence and the formation of water trees. It was found that for a relative distance of $2 \mu \mathrm{m}$, an applied electric field of $225 \mathrm{KV} / \mathrm{mm}$ is required for voids to attain plastic deformation, where voids achieve plastic deformation at a lesser electric field of $125 \mathrm{KV} / \mathrm{mm}$ if the relative distance between them is $0.5 \mu \mathrm{m}$. A smaller relative distance can be directly related to a high density of water voids in insulation, and thus it is of utmost importance to lower the density of voids as much as possible to ensure long lifetimes of power cables. The model in its current state is introductory. Future efforts will be devoted to enlarging the investigation by generalizing to numerous coalescences of voids and examining how these defects initiate corrosion of copper conductors.

Author Contributions: The article reports research which is part of the PhD Thesis of D.R.-J. supervised by M.D.-H. The conceptualization of the work and its organization were suggested by M.D.-H., D.R.-J., S.V. (master student) and E.-C.F. (2nd PhD student supervised by MDH) did the stimulations. All authors have read and agreed to the published version of the manuscript.

Funding: This research was partly funded by the ANR Project Offshore Energy Grids Monitoring and Diagnosis (Project EMODI, PI M. Drissi-Habti) and ERA-NET Project Flow-Cam. M. Drissi-Habti would like to thank deeply the funding organizations.

Conflicts of Interest: The authors declare no conflict of interest.

\section{References}

1. Disinhibit, M.; Raman, V.; Khadour, A.; Timorian, S. Fiber Optic Sensor Embedment Study for Multi-Parameter Strain Sensing. Sensors 2017, 17, 667.

2. Raman, V.; Drissi-Habti, M. Numerical simulation analysis as a tool to identify areas of weakness in a turbine wind-blade and solutions for their reinforcement. Comp. Part B 2016, 103, 23-39. [CrossRef]

3. Drissi-Habti, R.M. Numerical simulation of a resistant structural bonding in wind-turbine blade through the use of composite cord stitching. Comp. Part B Eng. 2019, 176, 107094.

4. Raman, V.; Drissi-Habti, M.; Limje, P.; Khadour, A. Finer SHM-Coverage of Inter-Plies and Bondings in Smart Composite by Dual Sinusoidal Placed Distributed Optical Fiber Sensors. Sensors 2019, 19, 742. [CrossRef] [PubMed]

5. Matine, A.; Drissi-Habti, M. On-Coupling Mechanical, Electrical and Thermal Behavior of Submarine Power Phases. Energies 2019, 12, 1009. [CrossRef]

6. Nexans, Promos. Available online: https://www.nexans.com/business/High-Voltage---Projects/Offshore) (accessed on 10 October 2020).

7. Yamada, Y.; Matsubara, H.; Fukunaga, S.; Yatsuka, K. Development and Reliability Study on High Voltage RCP-XLPE Cables. In Proceedings of the 7th IEEE/PES Transmission and Distribution Conference and Exposition, New York, NY, USA, 1-6 April 1979; pp. 386-390.

8. Chen, J.L.; Filippini, J.C. The morphology and behavior of the water tree. IEEE Trans. Electr. Ins. 1993, 28, 271-286. [CrossRef] 
9. Hvidsten, S.; Ildstad, E.; Faremo, H. Mechanisms causing nonlinear dielectric response of water treed XLPE cables, Conduction and Break-down in Solid Dielectrics, 1998. ICSD '98. In Proceedings of the IEEE 6th International Conference on Conduction and Breakdown in Solid Dielectrics, Vasteras, Sweden, 22-25 June 1998; pp. 73-78.

10. Dissado, L.A.; Fothergill, J.C. Electrical Degradation and Breakdown in Polymers; Peter Peregrinus Ltd.: London, UK, 1992; Volume 9.

11. Kim, C.; Duan, J.; Huang, X.; Kim, S.; Jiang, P.; Kim, H.; Hyon, S. Nu-merical analysis on water treeing deterioration of XLPE cable insulation using combination of FEM and Taguchi method. Eur. Trans. Electr. Power 2010, 20, 747759. [CrossRef]

12. Ross, R. Inception and propagation mechanisms of water treeing. IEEE Trans. Dielectr. Electr. 1998, 5, 660-680. [CrossRef]

13. Capaccioli, S.; Lucchesi, M.; Casalini, R.; Rolla, P.A.; Bona, N. Effect of water inclusions on charge transport and polarization in porous media. IEEE Trans. Dielectr. Electr. Insul. 2001, 8, 454-460. [CrossRef]

14. Crine, J.-P. Influence of electro-mechanical stress on electrical prop-erties of dielectric polymers. IEEE Trans. Dielectr. Electr. Insul. 2005, 12, 791-800. [CrossRef]

15. Sakamoto, M.; Yahagi, K. Influence of High Electric fields on Capacitance Measurments in PE. Jpn. J. Appl. Phys. 1980, 19, 253-259. [CrossRef]

16. Wang, Z.; Marcolongo, P.; Lemberg, J.A.; Panganiban, B.; Evans, J.W.; Ritchie, R.O.; Wright, P.K. Mechanical fatigue as a mechanism of water tree propagation in TR-XLPE. IEEE Trans. Dielectr. Electr. Insul. 2012, 19, 321-330. [CrossRef]

17. Meziani, M.; Mekhaldi, A.; Teguar, M. Impact of presence of water tree and microcavities on the electric field distribution in XLPE insulation. In Proceedings of the 4th International Conference on Electrical Engineering (ICEE), Boumerdes, Algeria, 13-15 December 2015; pp. 1-5.

18. Aluru Divya, T.; Rajagopala, K. Electrical field effect in the formation of water treeing in MV power cables. Int. J. Res. Eng. Technol. 2014, 3, 710-714.

19. Dubickas, V.; Edin, H. Dielectric model of water trees in an XLPE cable. In Proceedings of the International Symposium on Electrical Insulating Materials, Yokkaichi, Japan, 7-11 September 2008; pp. 448-451.

20. Neimanis, R.; Saha, T.K.; Eriksson, R. Determination of Moisture Content in Mass Impregnated Cable Insulation Using Low Frequency Dielectric Spectroscopy. In Proceedings of the IEEE Power Engineering Society Meeting, Singapore, 23-27 January; pp. 463-468.

Publisher's Note: MDPI stays neutral with regard to jurisdictional claims in published maps and institutional affiliations.

(C) 2020 by the authors. Licensee MDPI, Basel, Switzerland. This article is an open access article distributed under the terms and conditions of the Creative Commons Attribution (CC BY) license (http://creativecommons.org/licenses/by/4.0/). 